\title{
La construcción social de la mujer en el cristianismo e islam
}

The social construction of women in Christianity and Islam

\author{
Alexis Francisco Vizcarra Tacca' \\ Alison Serruto Castillo2
}

RECIBIDO: 9 DE FEBRERO DE 2020

ACEPTADO: 10 DE JUNIO DE 2020

\section{RESUMEN}

El estudio analiza la posición de la mujer en la religión cristiana e islámica presentado elementos importantes de ambas doctrinas religiosas que se caracterizan por etiquetar y guiar la vida de las mujeres dentro de sus sociedades bajo el yugo patriarcal, lo cual conlleva el establecimiento de normas que tienden a determinar la construcción social de los hombres y mujeres en base a doctrinas eminentemente patriarcales. Así mediante el estudio realizado en base al método del análisis de contenido de los discursos escritos, se logró dilucidar las diferencias de ambos

\footnotetext{
' Licenciado en Antropología, Educador social, Centro Juvenil de Diagnóstico y Rehabilitación Alfonso Ugarte Ministerio de Justicia, Universidad Nacional de San Agustín de Arequipa, Perú; alexisvizcarra1305@gmail.com, ORCID: https://orcid.org/0000-0002-8664-1524

2 Doctora en Ciencias Sociales. Socióloga, Docente, Universidad Católica Santa María de Arequipa, Perú; aserruto@ucsm.edu.pe, ORCID: https://orcid.org/0000-0001-7604-4278
} 


\section{2}

géneros en la dinámica social de ambas religiones, que fueron representadas por personajes que consideraban a la mujer como un ser inferior al hombre. Esta "inferioridad" se sustentaba en la aceptación de relatos expuestos en los libros sagrados de ambas doctrinas religiosas, que confluyen en la historia del "pecado original" al determinar que fue Eva la transgresora de la prohibición dada por Dios y su posterior incitación a Adán a caer en pecado. A partir de este relato bíblico que es considerado como un hecho real más allá de la imposibilidad de verificación, se somete a la mujer durante siglos al hombre siendo deshumanizada, hecho que en la actualidad aun presenta vestigios que se resisten a desaparecer a pesar de los movimientos sociales en pro de la igualdad de género en nuestras sociedades.

Palabras clave: religión, mujer, discriminación, sociedad

\section{ABSTRACT}

The study analyzes the position of the woman in the Christian and Islamic presented religion important elements of both religious doctrines that are characterized to label and to direct the life of the women within his low societies the patriarchal yoke, which bears the establishment of standards that they offer to determine the men's social construction and women on the basis of eminently patriarchal doctrines. That way intervening the study accomplished on the basis of the method of the analysis of contents of the written discourses, it was managed to elucidate the differences of both textiles in the social dynamics of both religions, that they were represented by characters that they regarded the man an inferior being the woman as. This inferiority was held in the approval of stories exposed in the sacred books of both religious doctrines, that God and his later incitement ebb into the history of the original sin when determining that the transgressor of given prohibition was Eva to Adán to incur in sin. As from this biblical story that is considered like one done real beyond the impossibility of verification, submits the woman during centuries to the man being dehumanized, fact that as of the present moment even shows vestiges that they stand against vanishing in spite of the social movements in behalf of the equality of kind in our societies.

Keywords: religion, woman, discrimination, society 


\section{Introducción}

La conformación de los sistemas religiosos ha dado lugar a la diferenciación social de los seres humanos dentro de la sociedad. Así desde los antiguos textos sagrados podemos encontrar claramente una acentuada brecha entre hombres y mujeres practicantes de creencias religiosas como el cristianismo y el islam que representan a dos de las cinco grandes religiones monoteístas en nuestras sociedades.

La religión definida por Frans de Waal es "la reverencia compartida hacia lo sobrenatural, lo sagrado o lo espiritual, así como hacia los símbolos, rituales y adoración con los que se los vincula" (Ambrosino, 2019).

Si deseamos remontarnos a sus orígenes, Robin Dumbar nos dice que las manifestaciones religiosas con base teológica solo tienen algunos miles de años desarrolladas principalmente por sociedades post-agrícolas mientras que las formas chamánicas se remontan a más de 500.000 años y son propias de los cazadoresrecolectores (Ambrosino, 2019).

El presente trabajo aborda episodios bíblicos como el pecado original descrito en el libro de génesis (antiguo testamento) y en el Corán. Más allá de eventos como el citado anteriormente se da a conocer la postura de los precursores de las doctrinas religiosas y textos que se utilizan como fuente de consulta para sancionar las transgresiones de la vida en sociedad. Timoteo, san Agustín, etc., consideraban a la mujer como un ser vil e inferior al hombre que no debía ser tratado en igualdad de condiciones en comparación con el hombre, así mismo la Sunnah (costumbre, practica, uso o tradición) es considerada la palabra del profeta Mahoma que fue recopilada de las conversaciones que mantenía con miembros del pueblo la cual no está presente en el Corán, pero que es utilizada por tradición para juzgar la transgresiones que cometen las personas. En países como Somalia la Sunnah es utilizada por las autoridades religiosas para ajusticiar mediante el apedreamiento (que conlleva la muerte de la sentenciada) a las mujeres que fueron infieles a sus esposos sin considerar que el Corán prohíbe esta práctica.

Así se realiza un estudio descriptivo analítico de las dos religiones tomando como base la posición de la mujer en la sociedad y su relación con las doctrinas religiosas que promueven las sociedades mediante las instituciones religiosas. 


\section{4}

\section{Método}

La metodología utilizada para la construcción del presente trabajo se enmarco dentro del análisis de contenido que se caracteriza por el estudio las ideas que se formulan a través del sentido semántico de las palabras (Duverger, 1974). Dado que el tema de investigación no se centró solamente en la recopilación de información referente al fin propuesto en la actividad investigativa, se requirió integrar la técnica bibliográfica con el análisis de contenido permitiendo dilucidar los caracteres intrínsecos de las doctrinas religiosas abordadas y el punto neurálgico representado por la diferenciación de género que existe en dichos preceptos.

\section{Resultados}

La realización de este estudio ha dado a conocer las similitudes del cristianismo y el islam en relación a la posición de las mujeres dentro de sus estructuras sociales, influenciadas por las doctrinas religiosas. A diferencia de Sáez (2010) que se centra en la religión islámica no analizando las condiciones de la mujer en las sociedades cristianas que la discriminaron desde los inicios de su establecimiento cultista llegando a categorizarlas como objetos de su propiedad deshumanizándolas. Del estudio realizado de los textos sagrados y doctrinarios (Sunnah) se ha logrado establecer que ambas sociedades siguen un mismo precepto patriarcal de dominación más allá de las diferencias culturales, sociales, económicas y religiosas. Por último, los trabajos futuros deberían dirigir su atención al análisis comparativo de los diferentes sistemas religiosos siguiendo el criterio de la objetividad que es indispensable al abordar temas con implicancias intrínsecas subjetivas de índole religioso, logrando superar posiciones estáticas doctrinarias. Para concluir se ha logrado abrir una ventana al conocimiento de la diferenciación de género desde una perspectiva histórica reconstructivita que posibilita ampliar el hecho investigado.

\section{La mujer y la religión: (acercamiento a la doctrina judeo - cristiana)}

Según la teoría hebrea (biblia judía - antiguo testamento-) en el libro del génesis Dios crea al hombre a su imagen y semejanza en el sexto día de la creación (Gn 1.27), el cual fue hecho a base de barro recibiendo el soplo divino, hecho que representa una estrecha comunión entre Dios y el hombre. 
Por el contrario, Eva viene a ser parte del cuerpo de Adán, puesto que según el relato bíblico Dios dice: no es bueno que el hombre este solo; le hare ayuda idónea para él (Gn 2.18). Sumiendo al hombre en un profundo sueño para tomar una de sus costillas y crear de esta a Eva la primera mujer, trayéndola al hombre, diciendo entonces Adán: "iEsta sí que es hueso de mis huesos y carne de mi carne! Será llamada "mujer" porque del hombre fue tomada" (Gn 2. 23).

Podemos apreciar en este versículo dos ideas importantes: Adán expresa que la mujer si es hueso de sus huesos y carne de su carne, frase que nos da un sentido de propiedad de la mujer hacia el hombre y concluye diciendo, será llamada varona porque del varón fue tomada.

Esta superioridad del hombre sobre la mujer también se observa en el capítulo 2, versículos 19 y 20 de la biblia, donde Dios da potestad a Adán para que de nombre a toda bestia del campo y ave del cielo reproduciéndose esta acción en la mujer, que no es nombrada como Adán por Dios. Además, la historia narrada en la biblia nos da a conocer la expulsión del paraíso de la pareja primigenia, hecho que se relaciona a Eva puesto que ella es tentada por la serpiente y rompe el único mandamiento que Dios impone al hombre: "Puedes comer de todos los árboles del jardín; pero del árbol del conocimiento del bien y del mal no comas; porque el día que comas de él, tendrás que morir" (Gn 2.17).

El relato nos muestra que la serpiente logró tentar a Eva. Diciendo: "¡Nada de pena de muerte! Lo que pasa es que sabe Dios que, en cuanto comáis de él, se os abrirán los ojos y seréis como Dios, versados en el bien y el mal" (Gn 3.5). Este episodio, muy misterioso, ha dado lugar a innumerables interpretaciones. La trama recuerda una representación mitológica bien conocida: la diosa desnuda, el árbol milagroso y su guardián, la serpiente (Eliade, 1999). A diferencia de otros relatos no se ve triunfante el logro de apropiarse del fruto prohibido que encerraba misterios divinos, todo lo contrario, la pareja es castigada por Dios siendo Adán víctima de la debilidad de Eva y su posterior incitación a que pruebe del fruto prohibido cayendo en pecado por su ingenvidad.

Según la doctrina cristiana, este episodio marca el inicio del sufrimiento de la humanidad, no solo por la pérdida del paraíso y la aparición de la condición humana, sino porque Caín asesina a su hermano Abel por envidia instaurándose el 


\section{6}

asesinato en la sociedades humanas, condenando Dios a Caín a vagar por el mundo y a no poder cultivar la tierra, este hecho según la religión judeo cristiana e islámica es resultado del pecado original provocado por Eva, que vuelve a ser citada por Timoteo en el nuevo testamento:

La mujer aprenda en silencio, con toda sujeción. Porque no permito a la mujer enseñar, ni ejercer dominio sobre el hombre, sino estar en silencio. Porque Adán fue formado primero, después Eva; y Adán no fue engañado, sino que la mujer, siendo engañada, incurrió en trasgresión. Pero se salvará engendrando hijos, si permaneciere en fe, amor y santificación con modestia. (Tim 2: 11-15).

Timoteo dictamina que la mujer debe aprender en silencio (su aprendizaje no debe resaltar), no debe enseñar ni ejercer ningún dominio sobre el hombre (no debe ser superior al hombre en ningún aspecto) porque Adán fue primero (Adán fue creado por Dios y Eva fue creada a partir de Adán) y Eva fue engañada (fue pervertida por la serpiente), acentuándose la debilidad de ella. En las escrituras mencionan que esta se salvaría engendrando hijos y manteniendo una conducta santa (la mujer tiene que salvarse puesto que está en pecado), es claro el mensaje que subyuga a la mujer al hombre resaltando que Eva fue quien cometió la transgresión que llevo al pecado original.

Podemos apreciar en otros versículos de la biblia esta imagen que debe ser impuesta a la mujer, así en 1 de corintios 14: 34-35, se prohíbe que las mujeres hablen en las asambleas y si desean aprender algo que le pregunten a sus maridos pues no está bien visto que las mujeres hablen en una asamblea. Esta restricción limita claramente la participación política de la mujer en las asambleas donde se discutían temas de importancia para la comunidad, siendo subordinadas indiscutiblemente al marido. Los padres de la iglesia no están ajenos de discriminar a la mujer como podemos ver en el siguiente párrafo de san Agustín de Hipona: "es Eva la tentadora de quien debemos cuidarnos en toda mujer... no alcanzo a ver que utilidad puede servir la mujer para el hombre, si se excluye la función de concebir niños" (Instituto asturiano de la mujer, 2010, p. 31).

A lo largo de la historia de la religión judeo cristiana se ha acentuado la sumisión y discriminación de la mujer en todos los aspectos de la vida social, limitando su participación y desarrollo personal al ser excluida y sometida al varón, basándose en 
preceptos de índole religioso que han determinado el desarrollo de las sociedades regentadas por la doctrina religiosa que tuvo un papel importantísimo en la conformación de la estructura social y su estratificación en la cual podemos ver una acentuada diferencia de género, que en la actualidad se intenta superar derribando las barreras edificadas en épocas anteriores.

\section{La mujer en el mundo islámico}

\section{La fase pre islámica}

Las sociedades pre islámicas paganas se caracterizaban por considerar a la mujer como un bien material que se podía comprar y vender, esta posición que sustentaba la mujer se basaba en que no "poseían habilidades para montar a caballo y pelear en batalla para proteger su tribu o clan". Podemos ver que la estructura social se caracterizaba por la maximización de la masculinidad y sus cualidades físicas que se sustentaban como signo de poder y dominación claramente de una sociedad patriarcal. Es necesario recordar que los primeros grupos humanos se encontraban permanentemente en conflicto tanto por el territorio como por los recursos naturales para la supervivencia, hecho que reforzaba la posición hegemónica del hombre en la jerarquía social.

Los estudios realizados ubican a los árabes dentro de la familia semítica, de acuerdo la clasificación lingüística que engloba pueblos tan diversos como: los judíos, hebreos, fenicios, sirios, babilónicos y asirios. Más allá de esta clasificación se puede establecer un tipo físico o antropomorfo de los árabes que se caracteriza en dos tipos según Mr. Girard:

El primero viene caracterizado por una estatura esbelta que generalmente no pasa de mediana; por miembros secos y nerviosos; por extremidades finas y por una cara larga y delgada en la parte inferior; la barba es contorneada, la boca pequeña, los dientes blancos y los labios delgados; la nariz, que es estrecha, se une a la frente directamente y toma una forma aguileña muy pronunciada, encorvándose en la extremidad como el pico de ave de rapiña; los ojos negros y bien rasgados, se abrigan bajo unas cejas poco desarrolladas y el cráneo es dolicocéfalo. Así está compuesto el tipo más general de los árabes; y así se le ve también entre los israelitas, los sirios y los egipcios antiguos y modernos. El segundo se distingue por una estatura 


\section{8}

más o menos alta, pero maciza y pesada; por unos miembros acentuadamente musculosos, por una cara más ancha y fuerte; por unas quijadas poderosas y con frecuencia prominentes; tiene la barba saliente, la boca rasgada, los labios grvesos, la nariz ancha, aguileña y abultada en la punta, los arcos superciliares marcados y muy poblados; los ojos grandes y negros; y la frente, recta y baja. Este tipo se halla de un modo completo en los sirios; también se ve entre los judíos, lo mismo que entre los árabes, particularmente los del Sud; igualmente existe entre los egipcios, bien que estos últimos tienen en las venas sangre de elementos africanos, como lo indican ciertos rasgos de su fisonomía y las proporciones del cuerpo (Le Bon, 1886, p.16).

El autor resalta la diferencia en la estatura, constitución física (delgada en la primera y robusta en la segunda), facciones del rostro bien marcadas que se complementa con la ubicación geográfica y determina una diferencia clara de dos tipos de árabes que se desarrollaron en Egipto: los egipcios antiguos (primer tipo) y egipcios modernos con influencia racial africana (segundo tipo). Más allá de los establecimientos geográficos específicos que hemos se debe establecer la propagación de este grupo étnico en términos generales, así podemos ubicar este grupo poblacional desde el continente africano hasta el continente asiático.

La forma de vida de los árabes se caracteriza en dos tipos básicos: los nómades o beduinos y los sedentarios. Los nómades se ubican desde Marruecos hasta Arabia dándonos a conocer una costumbre de vida antiquísima que se caracteriza por la organización tribal y la cría de ganado, actividad económica primaria que los empuja a una forma de vida trashumante que lleva al grupo a establecer tiendas de campaña estacionales en búsqueda de pastizales. El árabe sedentario desarrolla una forma de vida que implica los contactos entre gran diversidad de pueblos promoviendo el comercio y la conformación de alianzas y normas estables que rigen la vida de los pueblos y las posesiones de estos, que en el caso de los nómades no se desarrolla por su primitiva organización social que basa su sustento en la naturaleza y lo que esta pueda proveer a su actividad de pastoreo. El nomadismo y el sedentarismo también presentan un componente histórico que divide a los árabes en tres orígenes étnicos.

- El primer grupo étnico desapareció antes del islamismo. 
- El segundo grupo étnico es considerado descendiente de Joctan, (descendiente de Sem hijo de Abraham) siendo la raza árabe más pura que se instaló en Yemen.

- El tercer grupo étnico proviene de Ismael (hijo de Abraham con su esclava egipcia).

Esta división se basa en la biblia judeo cristiana, especialmente las dos últimas representadas por Joctan e Ismael que de acuerdo con los textos bíblicos son los antepasados de las doce tribus de Israel, pero los árabes consideran a Ismael como su antepasado en oposición a Isaac y Joctan.

Las Religiones Árabes antes de Mahoma

Los árabes como la mayoría de los pueblos de su época eran politeístas llegando a adorar tantos dioses como los griegos, siendo el astro sol una de sus principales divinidades. La Kaaba lugar sagrado de peregrinación de los árabes albergaba alrededor de 360 estatuas o imágenes de dioses entre las que figuraban las de Jesucristo y la Virgen María. Las cuales eran adoradas por los árabes, aun así entre los árabes existía el culto monoteísta que era promovido por la presencia de judíos y cristianos, que fue utilizado por Mahoma para la implantación del islam.

\section{Mahoma "El Profeta Elegido por Allah"}

Mahoma nace el 27 de agosto del año 570 en la ciudad de la Meca que era el centro de peregrinación de los árabes que acudían a adorar la Kaaba. Pertenecía al clan Qurasí y dentro de este a la tribu Banu Hasim (De la torre, 2005), su padre Abdalla (hijo de uno de los sumos pontífices de la Kaaba) fallece dos meses antes de su nacimiento y su madre Amina (hija de un jefe de tribu) fallece cuando él tenía seis años pasando al cuidado de su abuelo Abd - el - Mottabid que fallece dos años después quedando al cuidado de su tío Abu Talib que no pudo educarlo adecuadamente por dedicarse al comercio por lo que viajaba constantemente. Este episodio de la vida de Mahoma es reconocido por los árabes en la medida que éste siendo muy joven tuvo que sufrir la perdida de sus padres y quedar prácticamente a su suerte hecho que marco su carácter de hombre santo en el futuro.

A la edad de 25 años se casa con una rica viuda llamada khadidja que encomendó sus negocios a Mahoma, a pesar de la diferencia de edad (khadidja tenía cuarenta 


\section{0}

años cuando se casa con Mahoma de 25 años) él no tomó otra mujer mientras ella vivió, ella le dio cuatro hijas, Zaynab, Ruayyah, Umm Kulthum y Fátima, aparte de un hijo llamado Qasim que murió a corta edad (De la Torre, 2005). Durante la relación con khadidja realizo varios retiros espirituales en el monte Harra pues su insatisfacción con la religión politeísta era ya conocida por su esposa. Durante uno de estos retiros cuenta la historia que llego con el rostro desencajado diciendo lo siguiente:

Vagaba yo esta noche por la montaña, cuando la voz del ángel Gabriel ha resonado en mis oídos diciéndome: En nombre del Señor que ha criado al hombre, y que viene a enseñar al género humano lo que no sabe, Mahoma, tú eres el profeta de Dios, y yo soy Gabriel. Tales han sido las palabras divinas, y desde este momento he sentido dentro de mí la fuerza profética (Le Bon, 1886, p.40).

La revelación que el arcángel Gabriel había anunciado a Mahoma fue puesta en duda por él mismo que dubitativo pensó que estaba volviéndose loco o estaba poseído por los genios (seres intermedios entre ala y el hombre, hechos de fuego, podían ser benéficos o malignos). Volviendo a aparecer el arcángel Gabriel (mientras Mahoma era consolado por su mujer) diciendo: "iOh, tu que estas arropado! ¡Levántate y amonesta! ¡Y magnifica a tu señor! ¡Tú señor no te ha abandonado!" (Gail, 1988, p.17).

Desde ese día empezó su misión profética que mantuvo durante el resto de su vida recibiendo apoyo del rey cristiano de Abisinia cuando fue perseguido por sus enemigos, dándoles refugio y protección en dicha ciudad, la cual fue importante para la travesía del profeta que considero que era adecuado que un pueblo cristiano de protección al pueblo islámico.

Como se mencionó al principio de este apartado las religiones pre islámicas se caracterizaron por su carácter patriarcal, que se promovió por la inclemencia del territorio donde se desarrollaron necesitando la fortaleza del hombre para poder sobrevivir en su estado de nomadismo tribal. Con la llegada de Mahoma se modifica este principio patriarcal, aunque no implica que las mujeres tengan la posición de igualdad frente a los hombres hecho que mantiene la supremacía del hombre sobre las mujeres. 
Abordar el Corán nos lleva a plantear una serie de dicotomías basadas en la visión de investigadores como Fernández (2011) que presenta el siguiente análisis del Corán en torno a la poligamia:

Las observaciones coránicas sobre el matrimonio se complementan con distintas normas que regulan la poliginia. Es importante tener en cuenta, como otro elemento de desigualdad entre hombres y mujeres, que solo a ellos se les permite contraer matrimonio con varias mujeres, y que en ningún país islámico se acepta que las mujeres tengan varios esposos. De todos modos, el propio texto del Corán recomienda tener en líneas generales solo una esposa, bajo el argumento de que si un hombre tiene varias mujeres, le resultaría difícil ser equitativo y complacerlas a todas en la misma manera: "si teméis no ser equitativo con las dotes de las huérfanas, entonces casaos con otras mujeres que os gusten: dos, tres o cuatro. Pero si teméis no ser justos, casaos con una sola o recurrir a vuestras esclavas. Esto (casarse con una sola mujer) es los recomendable para no cometer alguna injusticia" (sura 4, aleya 3). Vemos por los tanto que el punto de vista que prevalece es el masculino: es el hombre el que elije cuantas, y que mujeres desea tener, y el que determina si podrá ser justo con todas en caso de que opte por casarse con más de una (Fernández, 2011 , p. 270).

El erudito islámico Rahman (2013) se refiere al mismo tema que aborda este pasaje del Corán especificando:

El hombre en casi todas las sociedades del mundo tiene una posición dominante y de autoridad en sus hogares por sus atributos y fuerza naturales. Teniendo en cuenta esta fuerza natural del hombre y suponiendo que una mujer pueda tener dos o más esposos, surgiría la competencia entre ellos por ver quién tiene la autoridad y el comando del hogar, lo que provocaría celos, ira y odio entre los esposos. Más aún, si una mujer pudiera casarse con más de un hombre, ¿̇quién sería el responsable legal del niño que nazca? ¿Qué consecuencia demográfica traería a la sociedad luego de varias generaciones de este arreglo? ¿Los hombres se mantendrían fieles a sus esposas en estas circunstancias o se inclinarían a la promiscuidad? Las respuestas son obvias. Ya que una mujer puede quedar embarazada una sola vez por año de un hombre a la vez, y un hombre sí puede dejar embarazada a varias mujeres al mismo tiempo, es más lógico y natural que un hombre tenga más de una mujer, que una 


\section{2}

mujer más de un hombre. Sobre todo, en la poligamia, el hombre es el responsable de proveer a sus esposas e hijos y sería poco práctico desde todo punto de vista que fuera al revés (Rahman, 2013, p. 72).

Visiones totalmente opuestas las de Fernández y Rahman, el primero resalta la imposibilidad de las mujeres de poder tener varios esposos a diferencia de los hombres que pueden tener más de una esposa si lo desean, pero cita un pasaje del Corán donde se recomienda no tener más de una esposa, puesto que al tener varias se podría ser injusto al atenderlas produciéndose desigualdad, el autor también da a conocer que es recomendable que el hombre posea a una de sus esclavas (existía la esclavitud de la mujer) hecho que pasa por alto dado que en tiempos de Mahoma las mujeres que no eran musulmanas podían ser esclavizadas a diferencia de la religión cristiana que de acuerdo a los preceptos establecidos de igualdad se buscó desterrar la esclavitud en todas sus formas bajo la premisa que todos eran hijos de Dios.

Rahman señala que la poligamia masculina se basa en la naturaleza intrínseca del hombre que representa la autoridad del hogar que no puede ser compartida con otro hombre y enfatiza sobre la paternidad de la prole que se engendraría dentro de un hogar poliándrico, ¿ Quién asumiría la paternidad de los hijos? o ¿̇łodos los esposos serian padres de todos los hijos? Se puede ver el caos que se generaría en la estructura familiar, además Rahman también resalta la misión y función proveedora del hombre para con su familia o żacaso la mujer mantendría a todos los hombres? o ¿̇todos trabajarían para proveerla de todo lo que necesita?

Posiciones disimiles que confluyen en un punto neurálgico del islam, la posición de la mujer dentro de la sociedad islámica frente al hombre que es la autoridad dentro del hogar y proveedor, hecho que sume a la mujer a una sola función, el cuidado de los hijos y la atención de su esposo por tener cualidades innatas de empatía y afecto que han de facilitarle la labor del hogar.

El castigo hacia la mujer (como ser apedreada y emparedada) que se publicita en los medios de comunicación nos da una imagen salvaje de la religión islámica que causa el total rechazo de la sociedad occidental. Revisando el Corán podemos conocer que se prohíbe asesinar a la mujer y se recomienda evitar la agresión en 
todas sus formas. Siendo la práctica del apedreamiento y emparedamiento reminiscencias de la época preislámica que fueron prohibidas en el Corán.

La mayoría de los maltratos que sufren las mujeres no están permitidos por el Corán y quienes practican estos abusos se basan en la Sunnah (costumbre, practica, uso o tradición) que alberga los hadices que después del Corán son utilizados para guiar la vida en sociedad, muchos de los hadices han sido cuestionados por considerarse que no fueron palabras del profeta Mahoma y han sido desechados, podemos encontrar más de 15.000 mil hadices que han sido recopilados por estudiosos de la religión musulmana. Entre los hadices podemos encontrar varios que se refieren a la mujer:

(6606) Este mundo es en verdad dulce y verde, y Allah os ha establecido en él como (Sus) representantes (califas) para ver como os comportáis. Entonces tened cuidado con este mundo, y tened cuidado con las mujeres, pues la primera prueba que tuvieron los Banû de Israel fue causada por las mujeres (Muslim, 2010, p.771). Los habitantes del infierno según los hadices recopilados por el Sahih Muslim (2010) son:

(6597) Ibn 'Abbâs relató: "Muhammad (B y P) dijo: «Pude mirar el Paraíso y vi que la mayoría de sus ocupantes eran pobres. Y pude mirar el Infierno y vi que la mayoría de sus ocupantes eran mujeresı"".

Entre los hadices se indica cómo se debe castigar el adulterio:

(4191) Ubâdah ibn Al-Sâmit relató: "El Mensajero de Allah (B y P) dijo: "Tomad (enseñanza) de mí, tomad de mí. Allah ha establecido una salida para ellas. (Para la fornicación de) el soltero con la soltera (se aplica la pena de) cien latigazos (a cada uno) y exilio por un año. Y (para el adulterio de) el casado con la casada son cien latigazos y apedreamiento (hasta la muerte)ı".

(4192) Ubâdah ibn Al-Sâmit relató: "Cuando el Profeta de Allah (B y P) recibía la revelación sentía su rigor y su rostro se transformaba. Un día en el que recibió la revelación, sintió también su rigor y cuando (terminó y) se sintió aliviado dijo:

"Tomad de mí. Allah ha establecido una salida para ellas. Para los casados con las casadas y los solteros con las solteras. Entonces para los casados (la pena por el adulterio es) cien latigazos y la lapidación con piedras (hasta morir). Y para los solteros (la pena por fornicar es) cien latigazos y exilio por un año" (Muslim, 2010, p.494). 


\section{4}

El primero de los hadices relata la visión que tuvo Mahoma del paraíso y del infierno, cuenta que la mayoría de las personas que estaban en el paraíso eran pobres, visión que influiría al momento de su muerte puesto que ordeno que todo el dinero que poseía fuera dado a los pobres diciendo "no sería adecuado para mí presentarme ante Mi Señor y este oro todavía entre mis manos" (Gail, 1988). Además, cuando dirigió su mirada a las personas que se encontraban en el infierno vio que la mayoría eran mujeres.

Al ser la población del infierno en su mayoría mujeres nos lleva a plantearnos que según la Sunnah estas tienden al pecado por no seguir las leyes reveladas en el Corán por el profeta, a diferencia de la Sunnah el Corán no hace referencia al género de los habitantes del infierno solo da a conocer los castigos que sufren los condenados en el infierno.

El segundo hadice hace referencia al pecado original cometido por Eva incitada por la serpiente (se cita a los banus - hijos - de Israel descendientes de Adán y Eva) al recordar que las mujeres por descendientes de Eva son una prueba para el hombre, recomendando que los hombres se cuiden de las mujeres.

Es interesante ver que la presunción de un hecho no comprobado estigmatice a la mujer en el islamismo como en el judeo - cristianismo. Una de las características de las religiones es creer sin ver (sin verificar o conocer) por lo que se asume que lo escrito es un hecho real más allá de lo fantástico que pueda ser, y no debe ser puesto en duda considerándose parte de la historia. Que lleva a que se trate a la mujer con mucha cautela y se cuide su comportamiento por ser débil ante las tentaciones pudiendo provocar la ira de Allah.

El tercer hadice que se cita muestra la igualdad entre hombres y mujeres ante la comisión de adulterio siendo castigados con 100 latigazos y condenados a morir apedreados y para los solteros (por fornicarios - se prohíbe las relaciones sexuales sino están casados -) cien latigazos y el exilio por un año. Podemos ver que la ley que dicta la Sunnah es aplicada sin distinción de género en el caso de transgresiones sexuales. Los castigos señalados no están contemplados en el Corán y no son aplicados en todos los países musulmanes siendo la republica de Somalia un ejemplo de los países musulmanes que castigan el adulterio como dicta la Sunnah. 
En la Sura IV, versículo 38 se resalta la superioridad del hombre ante la mujer por los bienes que proporcionan al casarse con ellas. Y se valora que la mujer tiene que ser sumisa y obediente y cuidar de los bienes de su esposo y si ésta fuese desobediente ha de ser reprendida como dicta la ley: será exhortada mediante la palabra citando el Corán, será apartada del lecho y por último será azotada. Pero tan pronto como ella se rectifique y obedezca no se deberá seguir con las acciones mencionadas pues Allah es elevado y grande.

Se puede seguir citando pasajes de las Sunnahs y el Corán que revelan una realidad tangible sobre la situación de la mujer en el mundo islámico que marca una línea clara entre hombres y mujeres y su rol dentro de la sociedad que se guía a diferencia de las sociedades occidentales (hacemos referencia a los países de religión judeo cristiana) por la doctrina religiosa representada por el Corán y las Sunnahs. Que se considera palabra divina (solo en el caso del Corán) que ha de guiar la vida de los pueblos.

\section{Conclusiones}

Primera conclusión: Siglos de oscurantismo sumieron a la humanidad en un estado de incertidumbre que fue lecho propicio para el surgimiento de doctrinas religiosas que se constituyeron en ley para regir la vida de los hombres en la esfera social, dictaminando una serie de preceptos "ideales" que debían de ser cumplidos sin cuestionamientos por la población, ese fue el principio de la desigualdad social (de género) en la vida de los pueblos, que dirigidos por pequeños grupos interpretaban y modificaban los textos sagrados de acuerdo a sus intereses particulares condenando a las mujeres a vivir en un estado de servidumbre y sobrecogimiento que duró más de mil años que fueron regidos por el judeo - cristianismo y el islamismo. Este hecho aún presenta reminiscencias de un pasado que se resiste a desaparecer en nuestros tiempos causando una serie de conflictos y movimientos sociales que son la expresión de un sentimiento exacerbado de situaciones que se atañen a una etapa que lentamente va quedando en el pasado en las sociedades occidentales que han establecido sistemas legales para desterrar cualquier tipo de desigualdad entre hombres y mujeres. 


\section{6}

Segunda conclusión: En el caso de los países musulmanes se ve la resistencia a modificar su organización social basada en los textos sagrados que son interpretados por los eruditos que se encargan de brindar justicia entre los habitantes. Esta justica de corte patriarcal representa en nuestro tiempo la oposición al "mundo civilizado" que promovemos mediante los medios de comunicación que dan a conocer la desigualdad en estas sociedades que a opinión de extranjeros son arcaicas e injustas por la mirada etnocentrista que poseen.

\section{Referencias}

Ambrosino, B. (23 de 06 de 2019). BBC. Obtenido de ¿ Cuál es el origen de las religiones y cómo evolucionaron? Recuperado de https://www.bbc.com/mundo/vertfut-48624547

De la Torre, I. (2005). Historia del islam. Madrid: LID editorial.

Duverger, M. (1974). Métodos de las ciencias sociales. Barcelona: editorial Ariel.

El Corán. (2012). España: Ediciones Brontes S. L.

Eliade, M. (1999). Historia de las creencias y las ideas religiosas: tomo I, de la edad de piedra a los misterios de Eleusis. Barcelona: Paídos.

Fernández, O. (2011). Las mujeres en el islam: Una aproximación. Brocar: cuadernos de investigación histórica, (35), 267-286.

Gail, M. (1988). Seis lecciones sobre islam. Buenos Aires: Ebila.

Instituto Asturiano de la Mujer (2010). Mujeres en la historia guía didáctica. Asturias: Gobierno del Principado de Asturias.

Le Bon, G. (1886). La civilización de los árabes. Barcelona: Montaner y Simon. Muslim, S. (2010). La Sunnah. Buenos Aires: Oficina de cultura y difusión islámica.

Rahman, A. (2013). La mujer en el islam: Refutando los prejuicios más comunes. España: Al-homaidhi P. Press.

Sáez, J. (2010). La mujer en el islam. Alicante: Universidad de Alicante. Santa Biblia. (1999). Brasil: Reina Valera. 